\title{
Temperature Modulated Nanomechanical Thermal Analysis
}

\author{
Alves, Gustavo Marcati A.; Bose-Goswami, Sanjukta; Mansano, Ronaldo D.; Boisen, Anja
}

Published in:

I E E E Sensors Journal

Link to article, DOI:

10.1109/JSEN.2018.2819898

Publication date:

2018

Document Version

Peer reviewed version

Link back to DTU Orbit

\section{Citation $(A P A)$ :}

Alves, G. M. A., Bose-Goswami, S., Mansano, R. D., \& Boisen, A. (2018). Temperature Modulated Nanomechanical Thermal Analysis. I E E E Sensors Journal, 18(10), 4001 - 4007.

https://doi.org/10.1109/JSEN.2018.2819898

\section{General rights}

Copyright and moral rights for the publications made accessible in the public portal are retained by the authors and/or other copyright owners and it is a condition of accessing publications that users recognise and abide by the legal requirements associated with these rights.

- Users may download and print one copy of any publication from the public portal for the purpose of private study or research.

- You may not further distribute the material or use it for any profit-making activity or commercial gain

- You may freely distribute the URL identifying the publication in the public portal 


\title{
Temperature Modulated Nanomechanical Thermal Analysis
}

\author{
Gustavo Marcati A. Alves ${ }^{\circledR}$, Sanjukta Bose Goswami, Ronaldo D. Mansano, and Anja Boisen
}

\begin{abstract}
The response of microcantilever deflection to complex heating profiles was used to study thermal events like glass transition and enthalpy relaxation on nanograms of the biopolymer Poly(lactic-co-glycolic acid) (PLGA). The use of two heating rates enables the separation of effects on the deflection response that depends on previous thermal history (non-reversing signal) and effects that depends only on the heating rate variation (reversing signal). As these effects may appear superposed in the total response, temperature modulation can increase the measurement sensitivity to some thermal events when signals are isolated. Initially, it was shown how the signal can be processed to extract reversing, total and non-reversing signals and how the temperature modulation affects the cantilever sensitivity to temperature. Then, this technique was used to study how the different aging times affects the non-reversing curve but has no effect on the reversing curve, enabling more precise extraction of glass transition (Tg) in aged samples. With non-reversing data at different aging times, we measured the aging rate by means of average relaxation time $(\tau)$ using the Cowie-Ferguson model, obtaining $\tau=348$ minutes for PLGA aged at $20{ }^{\circ} \mathrm{C}$ and at $50 \%$ RH. Tg for PLGA at 50\% RH was measured as $37.8^{\circ} \mathrm{C}$ using the reversing signal with $0.32{ }^{\circ} \mathrm{C}$ of variation between aging times.
\end{abstract}

Index Terms-Microcantilever sensor, thermal analysis, temperature modulation, glass transition, polymer.

\section{INTRODUCTION}

$\mathbf{T}$ EMPERATURE modulation (TM) can be associated with most of the thermal analysis techniques, like Differential Scanning Calorimetry (TMDSC) [1], [2], Dilatometry (TMDIL) [3], [4] and Dynamic Mechanical Analysis (TMDMA) [5], [6]. The working principle lies in the superposition of two heating rates: A constant underlying heating rate and a variable heating rate, normally with sinusoidal shape. The response of the material properties gets divided in

Manuscript received January 24, 2018; revised March 13, 2018; accepted March 22, 2018. Date of publication March 26, 2018; date of current version April 23, 2018. This work was supported in part by the Brazilian Agency CNPq through Grant 206605/2014-5, in part by the Center for Intelligent Drug Delivery and Sensing Using Microcontainers and Nanomechanics, and in part by the Danish National Research Foundation under Grant DNRF122 and Villum Fonden under Grant 9301. The associate editor coordinating the review of this paper and approving it for publication was Prof. Weileun Fang. (Corresponding author: Gustavo Marcati A. Alves.)

G. M. A. Alves and R. D. Mansano are with Integrated Systems Laboratory, Polytechnic School of São Paulo University, 05508-010 São Paulo, Brazil (e-mail: gmarcati@usp.br; mansano@1si.usp.br).

S. B. Goswami and A. Boisen are with the Department of Micro and Nano Technology, Technical University of Denmark, 2800 Kongens Lyngby, Denmark (e-mail: sbos@nanotech.dtu.dk; anja.boisen@nanotech.dtu.dk).

This paper has supplementary downloadable multimedia material available at http://ieeexplore.ieee.org provided by the authors. The Supplementary Material contains material that is not included within the paper itself. This material is $289 \mathrm{~KB}$ in size. two parts: one that responds to the constant rate called nonreversing part, other that responds only to variable heating rate called reversing part. The general equation for temperature modulated analysis is given by equation 1 .

$$
\frac{d P}{d t}=C \frac{d T}{d t}+f(T, t)
$$

Where $\frac{d P}{d t}$ is the time derivative material property $P$ or total part of the response. In case of TMDSC, $P$ represents heat flow. The $C \frac{d T}{d t}$ represents the reversing part, dependent on the temperature rate of change $\frac{d T}{d t}$, in case of TMDSC, C represents the material heat capacity. Finally, the term $f(T, t)$ is the non-reversing component that depends only on the absolute time and temperature.

The main use of the temperature modulation is to separate effects that can overlap in the thermal response. Examples of thermal events that are related only to non-reversing signals are: enthalpic relaxation, evaporation and curing. Effects that responds to temperature variation that can be seen by reversing signal are: glass transitions and melting [7]. TM techniques found many applications in pharmaceutical research and drug development [7], [8], like detection of polymorphic forms of drugs, to accurately measure the glass transition temperature ( $\mathrm{Tg}$ ) in the presence of overlapping effects like hydrationdehydration and to measure drug thermal transition in the presence of multiple excipients.

Recently, coated micromechanical structures have been used for thermal characterization of a variety of materials [9]-[15]. The main advantage lies in the high sensitivity, allowing the analysis of as little as few nanograms of material and consequently faster analysis due to reduced time to reach equilibrium [16]. When the silicon microcantilever is covered with a material that possesses different physical properties like thermal expansion coefficients and elastic moduli, the whole bilayer structure will bend, storing elastic energy [17], as a result of different amount of expansion between film and cantilever [18]. If those properties remain constant, the variation of the cantilever deflection in relation to the temperature will be linear. When thermal transition takes places, mechanical properties changes, causing deflection/temperature relation to change.

Frequently, some other event than thermal expansion also changes deflection. These events will happen at certain time and absolute temperature (kinetic events) causing polymer expansion or contraction, storing or releasing elastic energy (e.g. evaporation). When heating is linear, both effects, thermal expansion and kinetic events can change the rate of deflection 


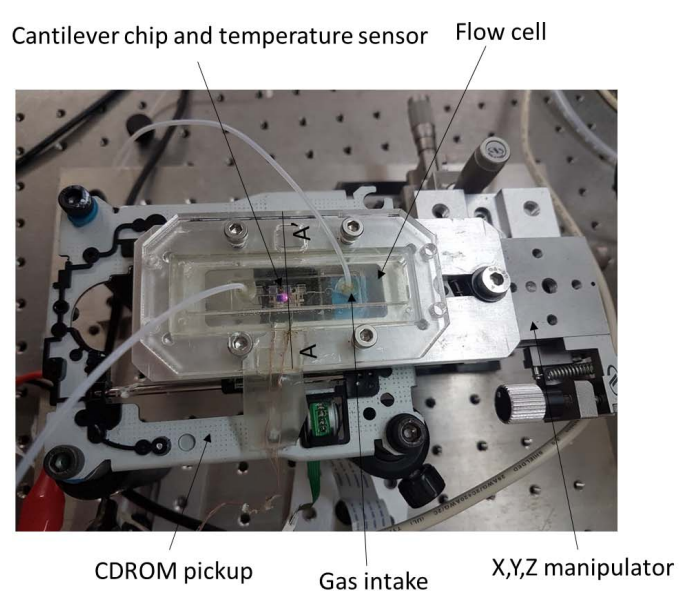

a)

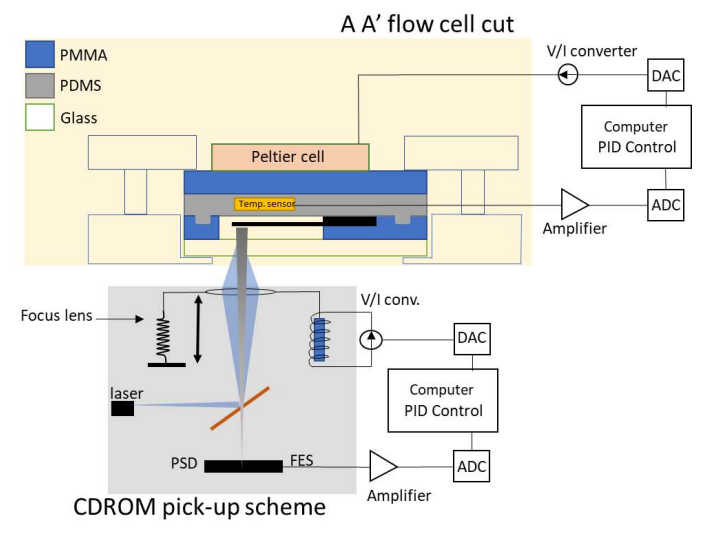

b)

Fig. 1. a) Photo of the platform used for cantilever readout. b) Flow cell cut with the layers and schematic of the CDROM optical pickup used for displacement measurement.

with time $\frac{d v}{d t}$, but when a sinusoidal temperature profile is applied, irreversible kinetic events does not respond to this signal and can be separated from pure thermal expansion deflection.

In this paper, microcantilever sensors spray coated with Poly(lactic-co-glycolic acid) (PLGA), a biodegradable polymer used in drug delivery systems and implantable devices, had their deflection sensitivity to temperature measured with an inexpensive CDROM pickup. The total part in the equation 1 will assume the form of the deflection variation with time $\left(\frac{d v}{d t}\right)$, the reversing part turns to $\gamma \frac{d T}{d t}$, where $\gamma$ is the deflection sensitivity to temperature due to thermal expansion in $\mathrm{nm} /{ }^{\circ} \mathrm{C}$ and the non-reversing part $f(T, t)$ is the subtraction of total and reversing part. We show that temperature modulation can be applied to the cantilever deflection response, enabling more precise and faster $\mathrm{Tg}$ extraction, splitting the overlapping effects of $\mathrm{Tg}$ and physical aging in reversing and non-reversing signals. This exempts previous thermal treatments to erase thermal history, thus the analysis becomes faster. In addition, the physical aging can be studied quantitatively, measuring the average relaxation time on the peak of the non-reversing signal.

\section{Materials And Methods}

\section{A. Cantilever Displacement Readout Using CDROM Pickup}

The system used for cantilever readout is depicted at figure 1 a). The main components are the flow cell where the cantilever chip is placed in presence of gas flow and the CDROM optical pickup for displacement measurement. The flow cell, whose schematics can be seen at figure $1 \mathrm{~b}$ ), is mounted on a XYZ micrometer stage for optical alignment. This cell is manufactured by milling $1 \mathrm{~mm}$ thick PMMA and fixing it with adhesive on a glass microscope slide. A thick PDMS layer $(\sim 500 \mu \mathrm{m})$ with an integrated PT100 temperature sensor is used for sealing the flow cell. The temperature actuation was realized with a Peltier cell placed on the top of the flow cell (not shown at the picture 1 a)), and it was controlled by a closed loop PID control in LabVIEW software. While PDMS is appropriated for sealing, enabling the use of liquid or gases, it does not provide the optimal heat transfer between Peltier cell and the cantilever chip, which can introduce small delay in the temperature control. The digital PID control presents typical settling time of 2 minutes for a $2{ }^{\circ} \mathrm{C}$ step, precision is $0.01{ }^{\circ} \mathrm{C}$.

For cantilever displacement measurement, a CDROM pickup was used and its operation as displacement sensor is well described [19]-[22]. The focus error signal (FES) used for displacement measurement is normally limited to few microns of range. As our cantilevers deflects in higher ranges, we used a closed loop PID scheme with the objective lens mounted on a voice coil to maintain the cantilever tip always on focus and used the voice coil current as displacement signal, reaching $\mathrm{mm}$ range of displacement with deflection noise of $10 \mathrm{~nm}$. Sampling of measurement and control loop time is controlled by acquisition time, typically we averaged $100 \mathrm{~ms}$ of acquisition, summed with processing time would lead 3 to 4 samples per second. Humidity was controlled and maintained at $50 \% \mathrm{RH}$ by computer, controlling the flow of humidified and dry nitrogen gas using MKS mass flow and Honeywell humidity sensor. All signal acquisitions were made with a National instruments NI USB 6009 board and all signal processing was made in LabVIEW 2014 software.

\section{B. PLGA Spray Coating}

PLGA Resomer® RG 502 obtained from Sigma Aldrich was dissolved in Dichloromethane (b.p. $40^{\circ} \mathrm{C}, \rho 1.33 \mathrm{~g} / \mathrm{mL}$ at $20^{\circ} \mathrm{C}$ ) at $0.5 \%$ weight concentration and spray coated on one side of the cantilever chip using an Exacta coat spray coater from Sonotek. Spray coater parameters was previously optimized [23] with the atomizer operating at $120 \mathrm{kHz}$ and $1.3 \mathrm{~W}$ of power, injecting polymer solution with a flow of $100 \mu \mathrm{L} / \mathrm{min}$. Cantilever arrays with 8 rectangular cantilevers were obtained from IBM with nominal width of $100 \mu \mathrm{m}$, length of $500 \mu \mathrm{m}$ and thickness of $1 \mu \mathrm{m}$. The XYZ controlled spray nozzle moves over the cantilevers and the thickness of the film is controlled by number of passes of the nozzle over the cantilevers and the distance between the nozzle and the 


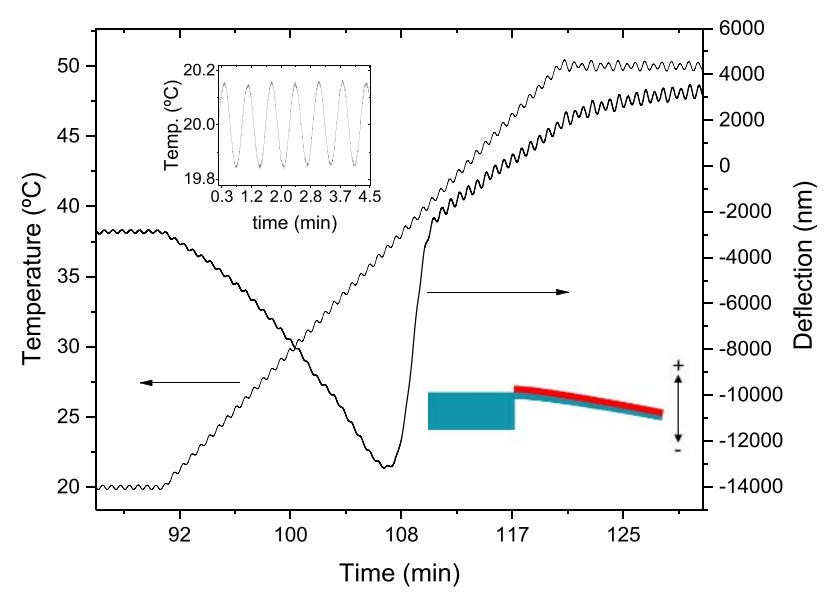

a)

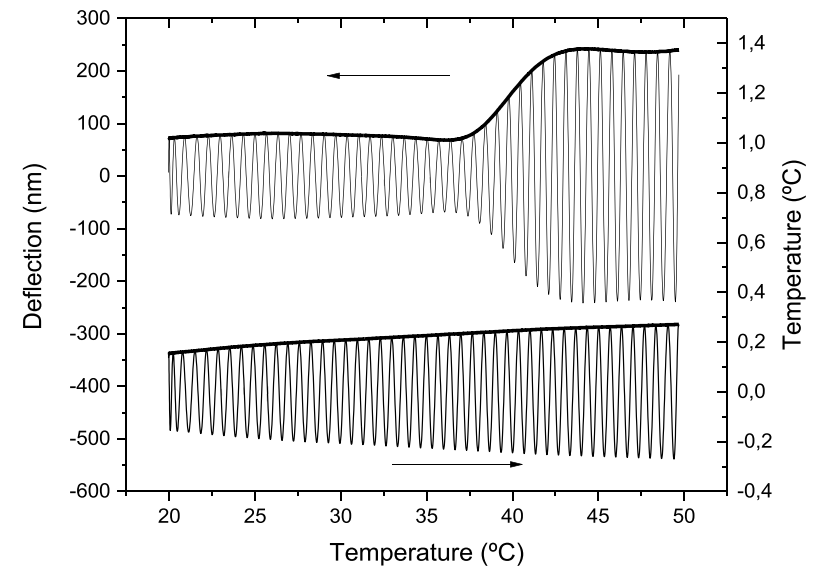

b)

Fig. 2. a) Temperature profile and resulting cantilever deflection. Inset shows modulated temperature with amplitude setpoint of $0.3{ }^{\circ} \mathrm{C}$ and frequency of $0.025 \mathrm{~Hz}$ (40 seconds period). b) Filtered temperature and deflection with a band pass filter of $0.03 \mathrm{~Hz}$ bandwidth between $0.025 \mathrm{~Hz}$. Continuous line is envelope extraction using Hilbert transformation.

cantilevers. For two passes the resulting film thickness was $1.93 \pm 0.04 \mu \mathrm{m}$ measured with the profilometer on a silicon piece placed at the same position of the cantilever chip.

\section{RESUlTS AND DISCUSSION}

\section{A. Temperature Modulated Nanomechanical Thermal Analysis}

An underlying heating rate of $1{ }^{\circ} \mathrm{C} \min ^{-1}$ was superposed by a sinusoidal signal with $0.3{ }^{\circ} \mathrm{C}$ of amplitude and $0.025 \mathrm{~Hz}$ of frequency ( 40 seconds period). The underlying heating was varied from 20 to $50{ }^{\circ} \mathrm{C}$ while the cantilever deflection was recorded. The temperature signal and cantilever deflection as a function of time can be seen at figure 2 a). The deflection signal shows the typical response of nanomechanical thermal analysis: initially, film expansion develops downward deflection, as the thermal expansion coefficient of polymer is greater than the silicon expansion coefficient. When $\mathrm{Tg}$ is reached (around 108 minutes), the elastic modulus of the film decreases several orders of magnitude and surface stress of the polymer relaxes.

At the deflection curve, it is possible to observe the oscillations generated by thermal modulation. To separate the modulated signal from the average signal, a band pass filter with $0.03 \mathrm{~Hz}$ bandwidth around $0.025 \mathrm{~Hz}$ was applied to the deflection and temperature signals at a postprocessing stage. The results can be seen in figure $2 \mathrm{~b}$ ) plotted against the underlying temperature. A Hilbert transformation was used to extract the envelopes of signals in function of underlying temperature and can be seen by the continuous line at the top of the curves. The deflection amplitude presents steep increase of more than 2-fold around $40{ }^{\circ} \mathrm{C}$ when glass transition of the PLGA is reached, while the temperature presents small linear increase.

To extract the total deflection sensitivity, the average deflection and average temperature of figure 2 a) were obtained using a Savitz-Golay filter with order 1. These signals were

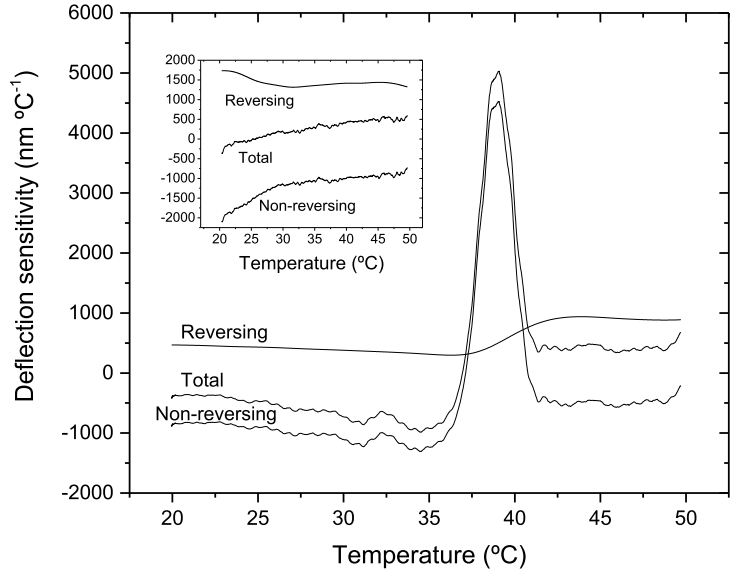

Fig. 3. Total, reversing and non-reversing part of deflection sensitivity to temperature as function of the underlying temperature. The inset shows sensitivities for the blank cantilever measured at the same conditions.

differentiated with respect to time and the results were divided to obtain the total deflection sensitivity showed at figure 3 . To obtain the reversing part, deflection envelope of modulated part, figure $2 \mathrm{~b}$ ), is divided by the temperature envelope. Finally, the non-reversing part is the subtraction of total part and reversing part.

The inset of figure 3 shows the sensitivity for a blank cantilever measured with the same temperature profile. The total signal of the blank cantilever is positive during the entire experiment, meaning that blank uncoated cantilever bends upward when heated due to anchoring effect to the substrate [18]. The total signal of the coated cantilever has its deflection sensitivity as a sum of anchoring stress and film stress. For temperatures lower than the Tg, the stress in the film is dominant and total signal is negative. When the polymer film is heated above the $\mathrm{Tg}$, the stress in the film decreases following its elastic modulus that decreases several orders of magnitude. In such event, the anchoring stress is dominant and 
the total sensitivity becomes positive. The anchoring stress also becomes dominant at the reversing signal after $\mathrm{Tg}$, but it is always positive as the reversing signal is obtained by dividing the amplitude of the oscillating signals and those are always positive.

The plot at figure 3 shows great similarities with the TMDSC plot of PLGA showed by Passerini and Craig [1]. In TMDSC measurements, the pulse at non-reversing signal around $\mathrm{Tg}$ is often attributed to enthalpic recovery of the material [1], [24], [25].

The enthalpic recovery is a reversible effect that is strictly related to the physical aging of the material when stored at temperatures lower than $\mathrm{Tg}$ [26]. At this situation, the material is at a non-equilibrium state, slowly dissipating energy towards the thermodynamic equilibrium. It is phenomenologically expressed by, for example, the decrease of volume and enthalpy over timer. The reversibility of the physical aging happens when the material is heated above the Tg. Due to higher molecular mobility, the dissipated energy is then recovered, leading to a sudden increase in the volume and enthalpy, which is manifested by a peak at non-reversing signal. To investigate if the kinetic peak in deflection sensitivity is responsive to enthalpic recovery variation, the samples were subject to isothermal aging, at varying times.

\section{B. Physical Aging of PLGA Studied by TM-NTA}

PLGA coated cantilevers were submitted to the temperature profile described in figure $4 \mathrm{a}$ ). The measurement underlying rate was $1{ }^{\circ} \mathrm{C} \mathrm{min}-1$ with temperature modulation frequency of $0.025 \mathrm{~Hz}$ and $0.3{ }^{\circ} \mathrm{C}$ of amplitude setpoint. Aging of the material was carried isothermally at $20{ }^{\circ} \mathrm{C}$ for $10,30,60$, 120 and 480 minutes at constant $50 \%$ humidity. The averaged deflection profiles are presented in figure 4b) where dots represent the blank cantilever deflection. One can observe that the curves are shifted downwards with the increase of the aging time as the polymer volume decreases over time. Consequently, the surface stress also decreases and the stress peak at $\mathrm{Tg}$ is greater for higher aging times. Yun et.al. [10] showed that when polymers are quenched after being heated above the $\mathrm{Tg}$, these stress peaks disappears and present a similar trend of increase when aged, as shown here.

In the figure 5 a) the non-reversing signal for various annealing times is shown. Increase in the peak due to enthalpic recovery is observed and is compatible with measurements made by TMDSC [24], [25]. In case of nanomechanical analysis presented here, we can attribute this effect to the relaxation volume that takes places when the polymer is left to age isothermally, causing the shift in downward initial deflection shown in figure $4 \mathrm{~b}$ ). Initially, when the polymer is heated, no difference in sensitivity is presented between aging times, however, when the $\mathrm{Tg}$ is reached, the cantilever that aged longer is in a position more deflected, causing a greater "jump" in the deflection when surface stress is released due to the fall in elastic modulus.

Since the reversing signal is measuring the instantaneous response of the cantilever to temperature, the reversing sensitivity, shown in figure $5 \mathrm{~b}$ ), does not depend on the state of the initial deflection and presents minimum variation between aging times. For this reason, this sigmoidal shaped curve can be used to extract the $\mathrm{Tg}$ of a material with large enthalpic recover characteristic peak. It exempts the requirements of quenching or perform a first measurement to erase thermal history, allowing better comparison of glasses aged close to $\operatorname{Tg}$ [24].

The Tg of aged PLGA was extracted using two methods. Using the deflection signal, described by Jung and Jeon [9] where two tangents lines are fitted in the deflection versus temperature plot. The other method, ASTM standard method for glass transition measurement by DSC [27] was applied in the reversing signal, using the midpoint as the $\mathrm{Tg}$. The extracted $\mathrm{Tg}$ versus aging time results can be seen in figure 6 . The same trend of $\mathrm{Tg}$ increasing several degrees with aging time was observed by Yun et.al. [10]. However, the Tg extracted using reversing signal showed minor variation of $0.32{ }^{\circ} \mathrm{C}$ around $37.8{ }^{\circ} \mathrm{C}$ with a small tendency to increase. These values are compatible to the Tg of PLGA measured at 50\% RH by DSC obtained by Blasi et.al. [28] with the value of $37.7^{\circ} \mathrm{C}$.

These results are compatible with the work of Tonchev and Kasap [24] where glasses were aged and $\mathrm{Tg}$ values obtained by total and reversing signal of TMDSC were compared. The value of the $\mathrm{Tg}$ obtained by total signal DSC shows greater variation than the ones obtained by reversing signal. The same reason for this variation can be attributed to the case of nanomechanical thermal response of the cantilever: the total signal, and therefore the measured $\mathrm{Tg}$, is dependent of sample initial state, if it suffered structural relaxation or not, while, reversing signal is dependent only on the instantaneous response.

The physical aging rate is often expressed as the average relaxation time $(\tau)$ : lower the relaxation time, faster the material will reach the equilibrium at a given temperature. The relaxation time can be measured using DSC enthalpic relaxation peak using the Cowie-Ferguson model [25], [29], [30], described by equation 2 .

$$
\Delta H(t)=\Delta H_{\infty}\left(1-\exp \left(-\frac{t}{\tau}\right)^{\beta}\right)
$$

Where $\Delta H(t)$ is the relaxation enthalpy, measured integrating the enthalpic relaxation peak in the total signal obtained by DSC, $\Delta H_{\infty}$ is the relaxation enthalpy for very long aging times (in equilibrium), $t$ is the aging time and $\beta$ is a parameter that characterizes the broadness of the relaxation process distribution $(0<\beta<1)$, smaller values mean broader relaxation distributions. As analogy with DSC measurement, non-reversing relaxation peaks of figure 5a) were integrated and plotted versus aging times and can be seen at figure $6 \mathrm{~b}$ ). We fitted the Cowie-Ferguson model substituting relaxation enthalpies for non-reversing integrated peaks. For non-reversing peak in equilibrium $\left(\Delta H_{\infty}\right)$, the sample was aged for 48 hours at $\mathrm{Tg}-10{ }^{\circ} \mathrm{C}\left(25^{\circ} \mathrm{C}\right)$.

The data fitted well to the model with the relaxation time for PLGA aged at $20{ }^{\circ} \mathrm{C}$ in $50 \% \mathrm{RH}$ measured to be $\tau=348$ minutes and $\beta=0.37$. Similar values were 


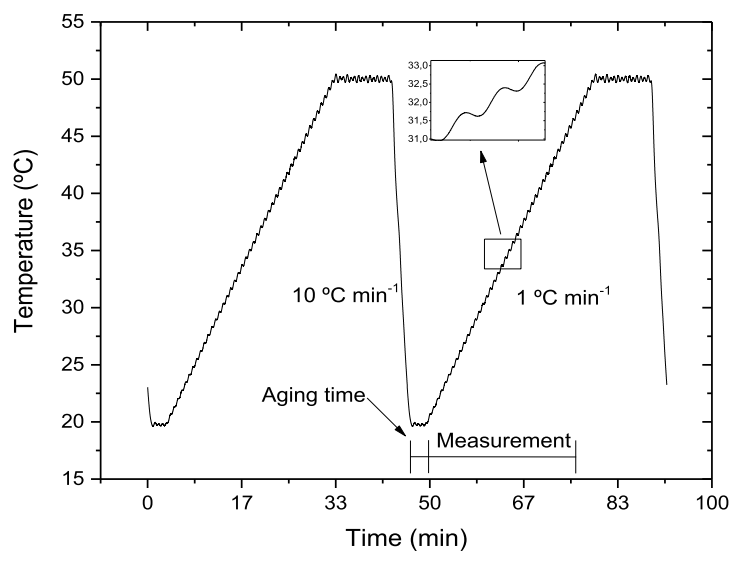

a)

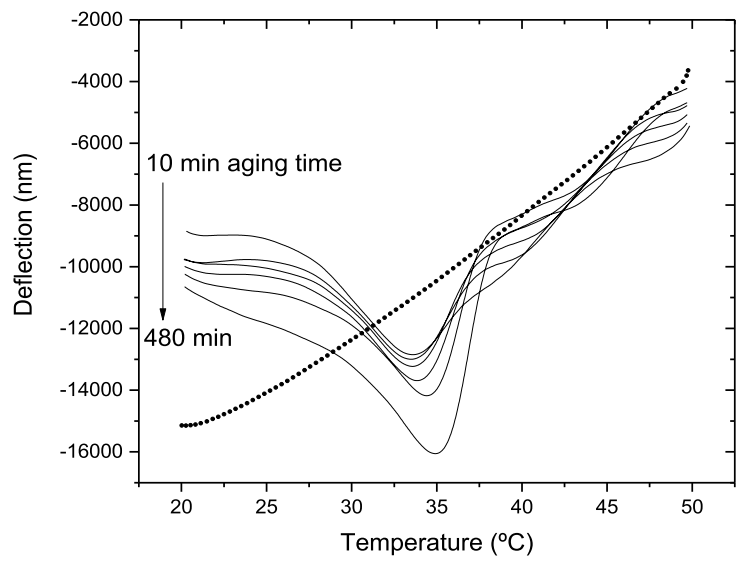

b)

Fig. 4. a) Temperature profile for the physical aging studies. Aging times was $10,30,60,120,240$ and 480 minutes. Underlying temperature rate was $1{ }^{\circ} \mathrm{C} \mathrm{min}-1$ from 20 to $50{ }^{\circ} \mathrm{C}$ maintaining 10 minutes at $50{ }^{\circ} \mathrm{C}$ then decreasing to $20{ }^{\circ} \mathrm{C}$ at $10^{\circ} \mathrm{C}$ min $^{-1}$. Modulation temperature amplitude setpoint was $0.3^{\circ} \mathrm{C}$ and frequency $0.025 \mathrm{~Hz}$. b) Averaged deflections obtained at different aging times increasing in direction of the arrow. Dots represents deflection of uncoated cantilever measured at the same conditions.

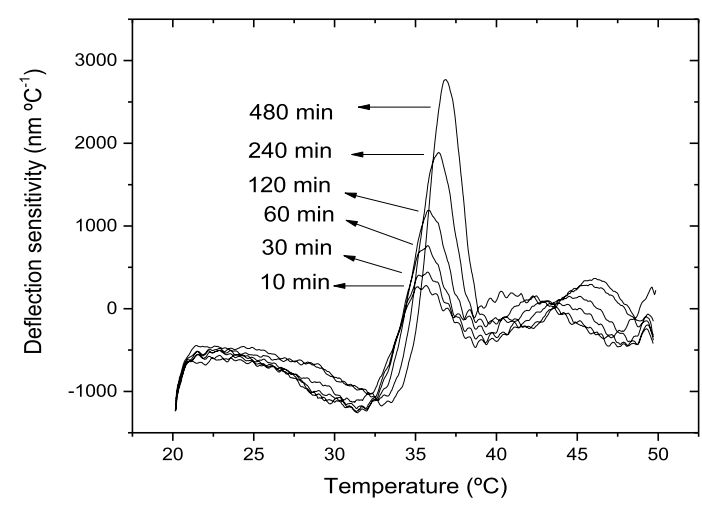

a)

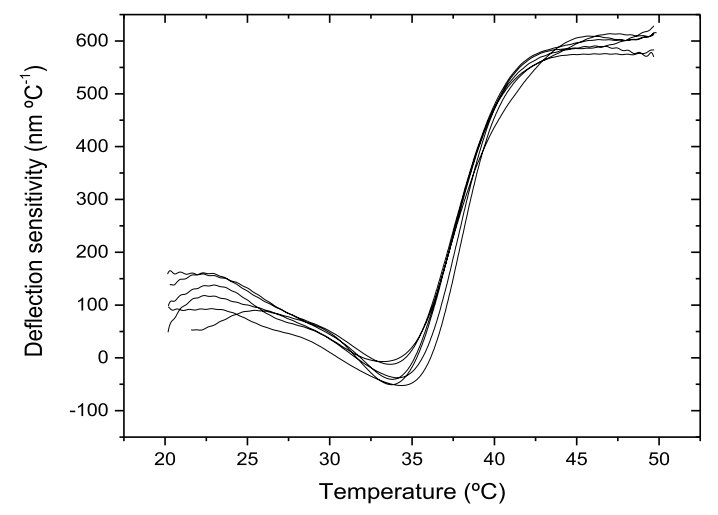

b)

Fig. 5. a) Non-reversing deflection sensitivity for different aging times. b) Reversing signal for different aging times.

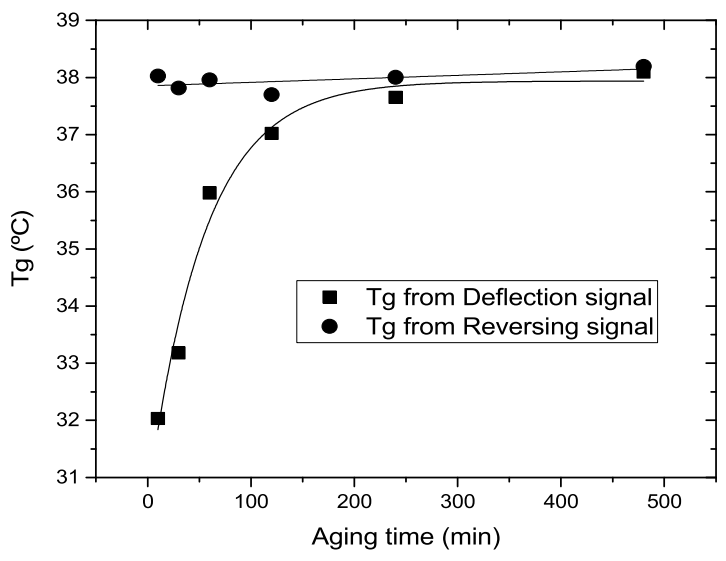

a)

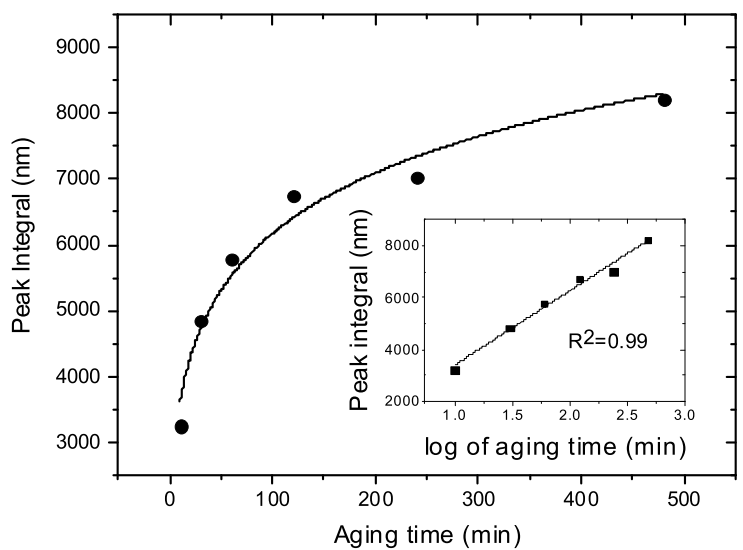

b)

Fig. 6. a) Tg measurement for different aging times using deflection signal and with reversing signal, lines are guides to eye. b) Non-reversing signal relaxation peak integral in function of aging time, line is Cowie-Ferguson model, inset shows peak integral versus log of aging time with linear fit.

found at [25] for PLGA microsphere aged at $\mathrm{Tg}-10{ }^{\circ} \mathrm{C}$. The inset of figure 6 a) shows that the peak integral follows a linear relation with the $\log$ of aging time with $\mathrm{R}^{2}=0.99$, being compatible with the model of Bauwens-Crowet and Bauwens [31] that relates relaxation enthalpy with log of aging time. 


\section{CONCLUSION}

The modulated temperature technique was applied to nanomechanical thermal analysis using a PLGA coated cantilever. When the modulated deflection signal was split from total deflection signal, a change in the amplitude of modulated signal was observed when the underlying temperature reaches Tg. This step in the temperature sensitivity with sigmoidal shape, is attributed to the fall in the elastic modulus of the film and can be used to measure the $\mathrm{Tg}$ of materials without the influence of thermal history, exempting thermal treatments like quenching to erase thermal history prior measurements.

The peak in non-reversing signal is dependent on relaxation or stresses that the cantilever coated suffered over time. When aged isothermally at various time, this peak increased its area proportionally to the $\log$ of aging time $\left(\mathrm{R}^{2}=0.99\right)$. This same behavior is observed in the peaks of kinetic signal of materials obtained by TMDSC. Moreover, we extrapolate the use of Cowie-Ferguson model used in DSC measurements to extract average relaxation time, integrating relaxation peak in the total signal, obtaining $\tau=348$ minutes for PLGA aged at $20{ }^{\circ} \mathrm{C}$ at $50 \% \mathrm{RH}$.

Besides the advantage of minimum use of materials and fast analysis, thermal analysis with cantilevers can yield more information which is interesting for material analysis, using for example, the resonant frequency and extracting the mass evolution during analysis or changes in the overall spring constant. It can also be used in conjunction with techniques like deflection modulation by infrared light to give more insights in the chemical bonds during thermal events.

\section{REFERENCES}

[1] N. Passerini and D. Q. Craig, "An investigation into the effects of residual water on the glass transition temperature of polylactide microspheres using modulated temperature DSC,' J. Control. Release, vol. 73, no. 1, pp. 111-115, May 2001.

[2] E. Verdonck, K. Schaap, and L. C. Thomas, "A discussion of the principles and applications of modulated temperature DSC (MTDSC)," Int. J. Pharm., vol. 192, no. 1, pp. 3-20, Dec. 1999.

[3] P. Kamasa, P. Myśliński, and J. Staśkiewicz, "Instantaneous coefficient of thermal expansion determined by temperature-modulated dilatometry," Czechoslovak J. Phys., vol. 54, no. S4, pp. 627-630, Dec. 2004.

[4] P. Myśliński, P. Kamasa, and A. Wassik, "Application of temperature modulated relative dilatometry. Temperatures of adhesion degradation," J. Thermal Anal. Calorimetry, vol. 65, no. 2, pp. 553-559, 2001.

[5] D. M. Price, "Modulated-temperature thermomechanical analysis," Thermochim. Acta, vols. 357-358, pp. 23-29, Aug. 2000.

[6] A. Wurm, M. Merzlyakov, and C. Schick, "Temperature modulated dynamic mechanical analysis," Thermochim. Acta, vol. 330, nos. 1-2, pp. 121-130, May 1999.

[7] M. M. Knopp, K. Löbmann, D. P. Elder, T. Rades, and R. Holm, "Recent advances and potential applications of modulated differential scanning calorimetry (mDSC) in drug development," Eur. J. Pharmaceutical Sci., vol. 87, pp. 164-173, May 2016.

[8] N. Coleman, "Modulated temperature differential scanning calorimetry: A novel approach to pharmaceutical thermal analysis," Int. J. Pharmaceutics, vol. 135, nos. 1-2, pp. 13-29, Jun. 1996.

[9] N. Jung and S. Jeon, "Nanomechanical thermal analysis with silicon cantilevers of the mechanical properties of poly(vinyl acetate) near the glass transition temperature," Macromolecules, vol. 41, no. 24, pp. 9819-9822, Dec. 2008.

[10] M. Yun, N. Jung, C. Yim, and S. Jeon, "Nanomechanical thermal analysis of the effects of physical aging on glass transitions in PS/PMMA blend and PS-PMMA diblock copolymers," Polymer, vol. 52, no. 18, pp. 4136-4140, Aug. 2011.
[11] M. Yun, C. Yim, N. Jung, S. Kim, T. Thundat, and S. Jeon, "Nanomechanical thermal analysis of photosensitive polymers," Macromolecules, vol. 44, no. 24, pp. 9661-9665, Dec. 2011.

[12] N. Jung, H. Seo, D. Lee, C. Y. Ryu, and S. Jeon, "Nanomechanical thermal analysis of the glass transition of polystyrene using silicon cantilevers," Macromolecules, vol. 41, no. 19, pp. 6873-6875, Oct. 2008.

[13] S. Bose et al., "Micromechanical string resonators: Analytical tool for thermal characterization of polymers," ACS Macro Lett., vol. 3, no. 1, pp. 55-58, Jan. 2014.

[14] S. Bose, S. Schmid, T. Larsen, S. Sylvest Keller, A. Boisen, and K. Almdal, "Micromechanical fast quasi-static detection of $\alpha$ and $\beta$ relaxations with nanograms of polymer," J. Polymer Sci. B, Polymer Phys., vol. 53, no. 15, pp. 1035-1039, Aug. 2015.

[15] M. Yun, I. Lee, S. Jeon, and J. Lee, "Facile phase transition measurements for nanogram level liquid samples using suspended microchannel resonators," IEEE Sensors J., vol. 14, no. 3, pp. 781-785, Mar. 2014.

[16] G. M. A. Alves, S. B. Goswami, R. D. Mansano, and A. Boisen, "Using microcantilever sensors to measure poly(lactic-co-glycolic acid) plasticization by moisture uptake," Polymer Test., vol. 65, pp. 407-413, Feb. 2018.

[17] M. Godin, V. Tabard-Cossa, P. Grütter, and P. Williams, "Quantitative surface stress measurements using a microcantilever," Appl. Phys. Lett., vol. 79, no. 4, pp. 551-553, Jul. 2001.

[18] W. Fang, H.-C. Tsai, and C.-Y. Lo, "Determining thermal expansion coefficients of thin films using micromachined cantilevers," Sens. Actuators A, Phys., vol. 77, no. 1, pp. 21-27, 1999.

[19] E.-T. Hwu, K.-Y. Huang, S.-K. Hung, and I.-S. Hwang, "Measurement of cantilever displacement using a compact disk/digital versatile disk pickup head," Jpn. J. Appl. Phys., vol. 45, no. 3B, pp. 2368-2371, Mar. 2006.

[20] A. C. Ceccacci et al., "Blu-Ray-based micromechanical characterization platform for biopolymer degradation assessment," Sens. Actuators B, Chem., vol. 241, pp. 1303-1309, Mar. 2017.

[21] E.-T. Hwu et al., "High-performance spinning device for DVD-based micromechanical signal transduction," J. Micromech. Microeng., vol. 23, no. 4, p. 45016, Apr. 2013.

[22] E.-T. Hwu et al., "An astigmatic detection system for polymeric cantilever-based sensors," J. Sensors, vol. 2012, Aug. 2011, Art. no. 580939.

[23] S. Bose, S. S. Keller, T. S. Alstrøm, A. Boisen, and K. Almdal, "Process optimization of ultrasonic spray coating of polymer films," Langmuir, vol. 29, no. 23, pp. 6911-6919, Jun. 2013.

[24] D. Tonchev and S. O. Kasap, "Effect of aging on glass transformation measurements by temperature modulated DSC," Mater. Sci. Eng., A, vol. 328, nos. 1-2, pp. 62-66, May 2002.

[25] J. J. Rouse, F. Mohamed, and C. F. van der Walle, "Physical ageing and thermal analysis of PLGA microspheres encapsulating protein or DNA," Int. J. Pharmaceutics, vol. 339, nos. 1-2, pp. 112-120, Jul. 2007.

[26] J. M. Hutchinson, "Physical aging of polymers," Prog. Polymer Sci., vol. 20, no. 4, pp. 703-760, 1995.

[27] Standard Test Method for Assignment of the Glass Transition Temperatures by Differential Scanning Calorimetry or Differential Thermal Analysis, document ASTM E1356-98, 1998.

[28] P. Blasi, S. S. D’Souza, F. Selmin, and P. P. DeLuca, "Plasticizing effect of water on poly(lactide-co-glycolide)," J. Control. Release, vol. 108, no. 1, pp. 1-9, Nov. 2005.

[29] J. M. G. Cowie and R. Ferguson, "Physical aging studies in polymer blends. 2. Enthalpy relaxation as a function of aging temperature in a poly(vinyl methyl ether)/polystyrene blend," Macromolecules, vol. 22, no. 5, pp. 2312-2317, Sep. 1989.

[30] R. Wungtanagorn and S. J. Schmidt, "Thermodynamic properties and kinetics of the physical ageing of amorphous glucose, fructose, and their mixture," J. Thermal Anal. Calorimetry, vol. 65, no. 1, pp. 9-35, 2001.

[31] C. Bauwens-Crowet and J.-C. Bauwens, "Annealing of polycarbonate below the glass transition temperature up to equilibrium: A quantitative interpretation of enthalpy relaxation," Polymer, vol. 27, no. 5, pp. 709-713, May 1986.

Gustavo Marcati A. Alves received the B.Tech. degree in microelectronics from the São Paulo State Faculty of Technology, Brazil, in 2006, and the M.Sc. degree from the Polytechnic School of São Paulo University, Brazil, in 2012, where he is currently pursuing the Ph.D. degree in micromechanical sensors. Since 2010, he has been a Laboratory Specialist with the Department of Electronic Systems Engineering, Polytechnic School of São Paulo University. 
Sanjukta Bose Goswami received the M.Tech. degree in polymer science and technology from the Indian Institute of Technology, Delhi, in 2011, and the Ph.D. degree on the use of micromechanical sensors as tools for polymer characterizations from the Department of Micro and Nanotechnology, Technical University of Denmark, in 2014. She is currently holding a postdoctoral position with the Department of Micro and Nanotechnology. Her current research interests are to characterize drug-polymer interactions and use micromechanical sensors for measuring polymer degradation for drug delivery applications.

Ronaldo D. Mansano received the degree in physics from the Pontifical Catholic University of São Paulo, in 1991, and the M.Sc. degree and the Ph.D. degree in electrical engineering from the University of São Paulo in 1993 and 1998, respectively. He was a Post-Doctorate in Electrical Engineering with the University of São Paulo in 2002. He is currently an Associate Professor with the University of São Paulo working mainly on the following topics: plasma deposition, plasma etching, new materials, microelectronics, nanotechnology, carbon nanostructures, fuel cells, and plasma processes.
Anja Boisen is a Professor and the Head of Nanoprobes Research Group with the Department of Micro and Nanotechnology, Technical University of Denmark. She is also heading a DNRF and Villum Centre of Excellence named IDUN-Intelligent Drug Delivery and Sensing Using Microcontainers and Nanomechanics. She has thorough knowledge on micromechanics and nanotechnology. Her research group focuses on development and application of micro and nano mechanical sensors and microfabricated systems for oral drug delivery. 